\title{
Crash Course: sintaxe e retórica visual na linguagem de um canal de cursos abertos no YouTube
}

\author{
Crash Course: visual syntax and rhetoric in the language \\ of an open course channel on YouTube
}

Fabiane Alves de Lima, Carolina Calomeno Machado

sintaxe visual, retórica visual, vídeo, educação multimídia

O presente artigo é resultado de uma pesquisa exploratória. Ele busca fazer uma análise de um canal educativo do YouTube, tomando como ponto de partida os pressupostos da Teoria Cognitiva da Aprendizagem Multimídia de Mayer (2012), que ressalta a importância do uso de múltiplos modos de representação na educação com base na forma como a cognição humana processa informação. O texto trata de modos de significação empregados retoricamente na linguagem visual (Durand, 1974) e busca suas categorias no material audiovisual analisado. Foi possível identificar alguns padrões a partir dessa análise, como o predomínio do uso das relações de similaridade e identidade no intuito de construir significado e conhecimento, e o emprego do humor como parte da proposta educacional do canal.

visual syntax, visual rhetoric, video, multimedia education

This article is the result of exploratory research. It presents an analysis of an educational channel on YouTube, taking as a starting point the assumptions of the Cognitive Theory of Multimedia Learning (2012), which highlights the importance of using multiple modes of representation in education based on the way in which human cognition processes information. The text deals with modes of signification used rhetorically in the visual language (Durand, 1974) and seeks to identify their categories in the audiovisual material. It was possible to identify some patterns from this analysis, such as the predominance of similarity and identity relationships in order to build meaning and knowledge, and the use of humor as part of the channel's educational proposal.

\section{Introdução}

O vídeo articula imagens em movimento de forma metalinguística, sobrepõe e sequencia elementos compositivos, e atua na audiência a partir de recortes de modos de ver. Desde muito antes da quase ubiquidade do acesso à internet permitir a transmissão dessa mídia em sua infraestrutura de rede, já se discutia a aplicação do vídeo na educação, ainda que com foco principal no tradicional ambiente da sala de aula (Morán, 1995).

No entanto, o vídeo como material didático na educação não-formal nem sempre pode contar com a mediação de um professor ou instrutor no momento da aprendizagem: nem sempre o acesso a esse material se dá nas melhores condições possíveis. Ao contrário de outros seus similares audiovisuais como o cinema, o vídeo educativo em materiais não-formais

Anais do $10^{\circ} \mathrm{CIDI}$ e $10^{\circ} \mathrm{CONGIC}$

Kelli C.A.S. Smythe, Rafael de Castro Andrade (orgs.)

Sociedade Brasileira de Design da Informação - SBDI

Curitiba | Brasil | 2021
Proceedings of the $10^{\text {th }} \mathrm{CIDI}$ and $10^{\text {th }}$ CONGIC

Kelli C.A.S. Smythe, Rafael de Castro Andrade (orgs.)

Sociedade Brasileira de Design da Informação - SBDI Curitiba | Brazil | 2021 
pode concorrer pela atenção do educando com uma série de outros dispositivos, atores e cenários, se assemelhando mais ao vídeo nas pequenas telas de celulares e computadores, e menos à projeção cinematográfica (Machado, 2011). Essa concorrência pela atenção do educando pode ser um fator a ser considerado na criação do material didático.

Este texto visa articular teorias de aprendizagem multimídia que abordem o tema, partindo daí para a análise dos elementos compositivos e retóricos dentro das possibilidades da linguagem do vídeo. Esses elementos possuem potencial para fazer a diferença na memória de longo prazo dos estudantes que buscam se educar informalmente (Cook, 2006). Tal investigação se vale do canal educativo Crash Course, especificamente a sua série sobre Ciência da Computação, como ponto de partida onde se articulam categorias analíticas da retórica visual, bem como as suas contingentes interações com outros modos de representação, como verbal e auditiva. A intenção com este trabalho é desenvolver um estudo para embasar análises posteriores, tendo como ponto de partida teorias de aprendizagem e linguagem visual.

\section{A Teoria Cognitiva da Aprendizagem Multimídia}

O design de materiais para aprendizagem em ambientes multimídia - ou seja, onde o conhecimento é codificado em mais de um formato midiático - precisa ser compatível com o funcionamento da cognição humana, caso contrário pode estar fadado ao fracasso. É preciso levar em conta o funcionamento da memória em conjunto com os canais sensórios através do qual o estudante acessa o conteúdo. A Teoria Cognitiva da Aprendizagem Multimídia de Mayer (2012) oferece esse fundamento, através de um modelo cognitivo que considera as interações entre memória de trabalho e de longo prazo, e as diferenças de processamento das mensagens e seus vários modos de representação.

Essa teoria possui três pressupostos. O primeiro é o pressuposto do duplo canal, baseado na teoria de Paivio (1986), que afirma que material visual/não-verbal e verbal/auditivo são processados em áreas diferentes do cérebro; porém, ambos os canais trocam informação entre si, de modo que informação inicialmente processada por um canal pode ser processada posteriormente por outro. O segundo pressuposto é baseado na teoria da carga cognitiva de Sweller (2012), que aponta que a memória de trabalho humana é limitada e processa entre quatro a sete unidades de informação por vez; isso significa que nossa atenção se foca apenas em partes da mensagem codificada, e que informações mais complexas precisam ser agrupadas para que possam ser processadas como unidades únicas de informação. O terceiro pressuposto afirma o caráter ativo da aprendizagem e indica caminhos para o design: humanos se engajam ativamente nos processos cognitivos em direção a criação de esquemas mentais coerentes da realidade que se the apresenta.

Todos esses pressupostos podem funcionar como pontos de partida para a criação de material didático, visto que oferecem pistas a respeito de como esse material precisa ser codificado, baseado na forma como ele é decodificado. Dado que é a partir de modelos 
mentais que os humanos fixam conhecimento na memória de longo prazo, é função do educador auxiliar o estudante na construção desses modelos. Assim, além de se atentar para as formas em que a cognição dos estudantes seleciona, organiza e integra as diferentes representações verbais, esquemáticas e pictóricas, educadores também podem se valer de diferentes estruturas informacionais para a criação desses materiais. Essas estruturas permitem que a informação seja acessada por meio de comparações, generalizações, hierarquizações etc, auxiliando o registro do conhecimento na memória de longo prazo (Mayer, 2012).

\section{Esquemas Cognitivos e Modos de Representação}

Ainda que a memória de trabalho tenha um processamento limitado, o poder de registro da memória de longo prazo tem se demonstrado inesgotável. Sweller (2012) define a aprendizagem como mudanças que se efetivam na memória de longo-prazo do aprendiz. As informações ali armazenadas atuam criticamente na construção das habilidades do estudante necessárias à resolução de problemas; sem alterações na memória de longo prazo, não existe aprendizado.

A principal função do design para educação é, portanto, superar as limitações da memória de trabalho através de suas ferramentas de representação gráfica. A compreensão é construída através de modelos e esquemas mentais que articulam informações que, sozinhas, poderiam esgotar o processamento cognitivo do estudante. Esquemas ajudam-no a não precisar apelar para tentativa e erro na construção de seus próprios modelos mentais no momento da aprendizagem, dado que funcionam como uma central executiva para a memória de trabalho, auxiliando-a na manipulação da informação e seu posterior registro na memória de longo prazo (Oakley, 2014).

$\mathrm{O}$ uso de imagens e o arranjo formal dos diferentes elementos compositivos ajudam os estudantes a criarem conexões entre os diferentes estímulos - verbais e não verbais - que acessam. A Teoria Cognitiva da Aprendizagem Multimídia atesta, portanto, o importante papel dos diferentes modos de representação para a criação de material educacional (Cook, 2006; Mayer, 2012). A produção desses materiais exige que esses conhecimentos sejam codificados de modos que sejam facilmente compreensíveis pela audiência. Tal tarefa "exige conhecimentos ligados não só a representação visual, mas também a noções de design de interface, arquitetura de informação, programação, animação, percepção visual e cognição" (Andrade, 2020. P. 32).

Além desse caráter estruturante das informações que as imagens possuem e thes conferem, através delas também é possível articular outros aspectos retóricos da visualidade, como é o caso das figuras de linguagem. Baseando-se no trabalho de Roland Barthes, Jacques Durand (1974) propõe duas grandes famílias de figuras de linguagem retóricas em uso na linguagem visual: metáboles são relativas ao significante e atuam na comparação ou substituição de um significante pelo outro (compreende as figuras de metáfora, metonímia, analogia etc), enquanto que as parataxes são relativas ao significado e ocorrem nas quebras do discurso, modificando as relações existentes entre os signos (elipse, suspensão, anacoluto etc). 
Quadro 1: Classificação das figuras de retórica, baseado em Durand (1974).

\begin{tabular}{|c|c|c|c|c|}
\hline RELAÇÕES & Adjunção & Supressão & Substituição & Troca \\
\hline Identidade & Repetição & Elipse & Hipérbole & Inversão \\
\hline $\begin{array}{l}\text { Similaridade } \\
\text { De forma ou conteúdo }\end{array}$ & $\begin{array}{c}\text { Rima } \\
\text { Comparação }\end{array}$ & Circunlocução & $\begin{array}{l}\text { Alusão } \\
\text { Metáfora }\end{array}$ & $\begin{array}{l}\text { Hendíadis } \\
\text { Homologia }\end{array}$ \\
\hline Diferença & Acumulação & Suspensão & Metonímia & Assíndeto \\
\hline $\begin{array}{l}\text { Oposição } \\
\text { De forma ou conteúdo }\end{array}$ & $\begin{array}{c}\text { Emparelhamento } \\
\text { Antítese }\end{array}$ & $\begin{array}{l}\text { Dubitação } \\
\text { Reticência }\end{array}$ & $\begin{array}{l}\text { Perífrase } \\
\text { Eufemismo }\end{array}$ & $\begin{array}{l}\text { Anacoluto } \\
\text { Quiasmo }\end{array}$ \\
\hline $\begin{array}{l}\text { Falsas homologias } \\
\text { Duplo sentido ou paradoxo }\end{array}$ & $\begin{array}{l}\text { Antanáclase } \\
\text { Paradoxo }\end{array}$ & $\begin{array}{l}\text { Tautologia } \\
\text { Preterição }\end{array}$ & $\begin{array}{l}\text { Trocadilho } \\
\text { Antífrase }\end{array}$ & $\begin{array}{l}\text { Antimetábole } \\
\text { Antilogia }\end{array}$ \\
\hline
\end{tabular}

Esse mesmo autor descreve quatro operações fundamentais da retórica realizadas por essas figuras: adjunção, supressão, substituição e troca (quadro 1). A partir dessas operações, se estabelecem entre os elementos constituintes de uma proposição as seguintes relações possíveis: identidade, similaridade, oposição e diferença, além das falsas homologias, que de certa forma infringem as relações propostas pelas outras categorias e podem ser percebidas, por exemplo, no uso de trocadilhos. Ainda que o trabalho de Durand tenha se proposto à análise do discurso publicitário impresso, sua classificação também pode ser empregada em outros meios onde as imagens têm precedência - como é o caso da educação tecnologicamente mediada pelo audiovisual.

\section{O canal Crash Course}

A proposta aqui é realizar um estudo fundamentado na Teoria Cognitiva da Aprendizagem Multimídia a partir de uma análise do canal educativo do YouTube Crash Course. Criado em 2012, ele surgiu a partir de uma iniciativa da plataforma, que disponibilizou US $\$ 100$ milhões para financiar canais que se propusessem a criar conteúdo original no YouTube. As primeiras séries do projeto abordavam conteúdos de História e Biologia, apresentados pelo escritor americano John Green e seu irmão Hank, respectivamente. Logo o canal alcançou notoriedade, acumulando mais de um bilhão de visualizações e 12 milhões de inscritos (Leib, 2012; Zipkin, 2018).

O Crash Course é produzido por uma parceria entre a produtora Complexly dos irmãos Green, a direção criativa do estúdio de animação Thought Café e o PBS Digital Studios, um braço do canal de televisão americano PBS que investe na produção de conteúdo educativo na internet e produz algumas das suas séries. Ao longo dos anos, o canal cresceu, incorporou novos apresentadores e temas, e atualmente possui 38 séries. Abrangendo conteúdos que vão de Literatura a Estatística, passando por Inteligência Artificial e Zoologia, cada vídeo tem entre dez e quinze minutos, com algumas listas de reprodução sendo divididas em temporadas e contendo mais de cinquenta vídeos cada. Existem também minisséries com conteúdos específicos, conteúdos direcionados especificamente a crianças, conteúdos em idiomas como o árabe e parcerias com universidades. 
Figura 1: Alguns dos vídeos do canal Crash Course. Fonte: das autoras.

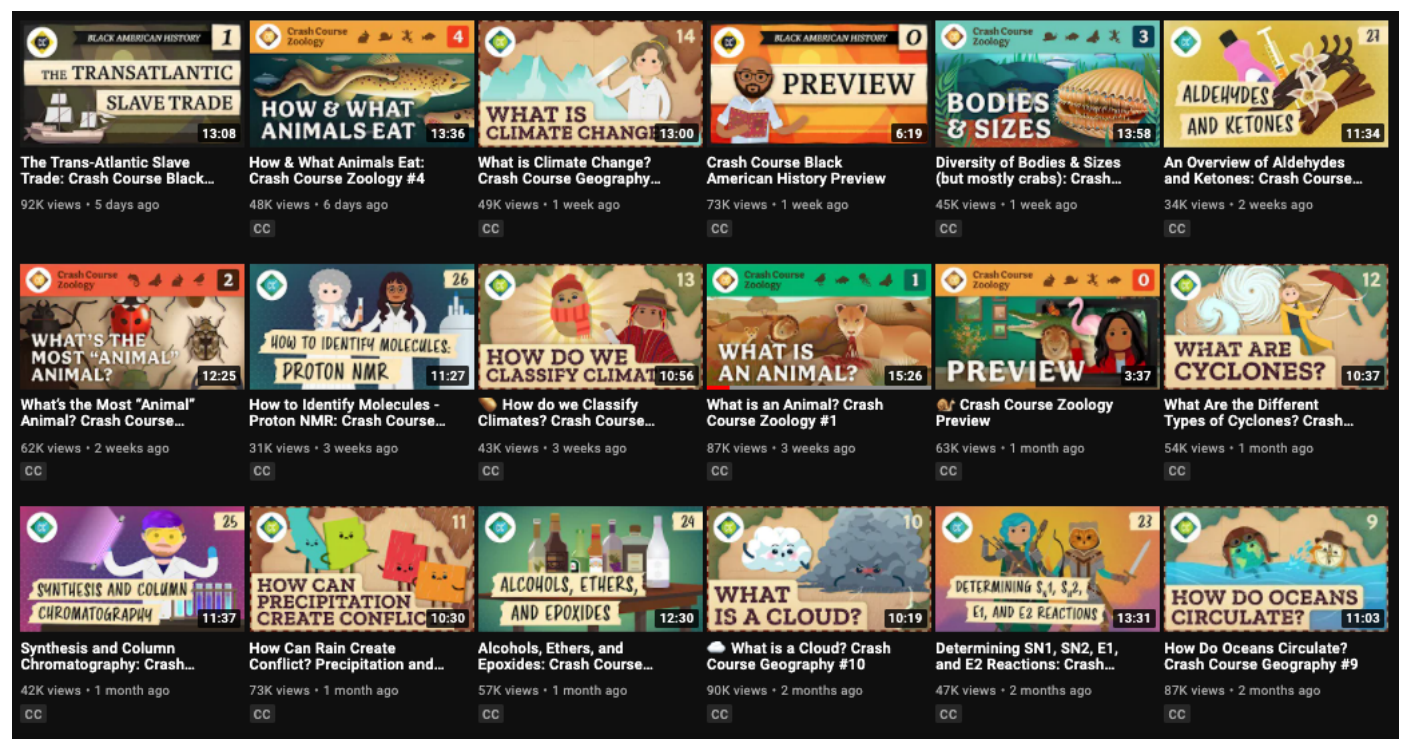

Os vídeos das séries do canal, enquanto conteúdo educativo, têm formatos bastante distintos ainda que dentro de uma estrutura internamente coerente: os vídeos começam com uma introdução, uma contextualização do conteúdo dentro da sequência pedagógica programada, exposição dos conceitos ou fatos intercalados com exemplos, e encerramento com uma sumarização rápida do tema tratado e uma chamada para o próximo vídeo. Grande parte do material corresponde a explicações do apresentador ou apresentadora, acompanhadas de pequenas animações; animações mais longas por vezes ilustram com linguagem pictórica, verbal e esquemática algum aspecto mais importante ou um conceito específico do conteúdo. Algumas intervenções textuais também acontecem no meio do vídeo, destacando citações de autores ou conceitos dignos de nota.

Dado que o projeto tem já alguns anos e muitos profissionais envolvidos na sua concretização, é possível notar que a produção do Crash Course desenvolveu uma linguagem particular e reconhecível. Trata-se não apenas de uma linguagem própria no sentido de uma identidade visual e estilo gráfico coesos, mas também no que diz respeito às suas piadas e "gags" internas - como a dos Mongóis, uma piada recorrente da primeira série de História, e que aparece de vez enquanto em outras séries para destacar exceções mesmo em conteúdos não diretamente relacionados a este grupo - e à relação com sua fiel audiência. Além das visualizações, outras marcas do sucesso do canal são os prêmios e indicações que ele tem recebido em categorias educativas ou de divulgação científica, e o emprego que estudantes do ensino médio têm feito de seu material para estudar para os exames nacionais, equivalentes ao ENEM brasileiro, nos Estados Unidos (Jaworski, 2012; The Webby Awards, 2018).

\section{Materiais e Métodos}

A intenção do presente estudo é realizar uma análise dos elementos sintáticos e semânticos presentes nas representações visuais do canal Crash Course com base nas suas características 
retóricas. Uma vez que se tratam de conjuntos de vídeos estruturados no entorno de um tema específico, onde a compreensão de um assunto depende e se constrói a partir da compreensão dos temas predecessores, faz-se necessário realizar um recorte desse conteúdo passível de análise. Assim, optou-se por restringir esta análise a um pequeno conjunto de vídeos de uma série temática específica do canal: Crash Course Computer Science. A série foi escolhida pelo potencial interdisciplinar do tema e pela possibilidade de retratar conceitos com muitas camadas de abstração, uma característica inerente da Informática. Essa série foi ao ar em 2017 e é apresentada por Carrie Anne Philbin, uma professora britânica da disciplina e divulgadora científica da Raspberry Pi Foundation (RaspberryPi.org, 2021).

Dos 40 vídeos que compõem a série em questão, optou-se por selecionar um conjunto de três deles, abarcando alguns dos conceitos básicos essenciais para entender a disciplina da Computação, ainda que o aprofundamento posterior desse entendimento dependa de uma escolha de carreira do estudante e do nível de abstração que o futuro profissional necessitará lidar em sua atuação. Esses vídeos compõem alguns dos primeiros conceitos técnicos apresentados na série, após uma contextualização histórica do assunto, e abordam lógica booleana, lógica binária e unidades de processamento aritmético e lógico, buscando desvendar para o estudante de que modo os pulsos elétricos dessas máquinas calculadoras são convertidos em informação.

O primeiro passo para essa análise foi assistir os três vídeos pré-selecionados para uma compreensão geral não apenas do conteúdo, mas também dos modos de simbolização dos seus conceitos. A partir desse primeiro acesso, foi possível notar um uso bastante recorrente de imagens em vídeo - para além das sequências com a apresentadora - como modo de ilustrar exemplos ou situações, combinadas com o uso de animações de caráter figurativo e esquemático. Por vezes, vídeo e animações atuam de modo integrado, complementando ou ilustrando um conceito que está sendo tratado naquele momento. Essas representações visuais esquemáticas, por mais que às vezes se tratem de unidades completas de informação, são apresentadas em porções. Os recursos animados permitem destaque imediato em trechos importantes ou o retrato de uma sequência específica de fatos ou processos.

Desse primeiro contato com o material audiovisual com intento de análise, partiu-se para a sua decupagem, buscando desmembrar os seus diferentes componentes informacionais, com destaque especial para aqueles pertinentes ao tema. Dada a quantidade de informação em um único vídeo da sequência e do tempo disponível para a realização do presente estudo, optouse por restringir a análise um pouco mais, focando no primeiro dos vídeos, e buscando, a partir de sua análise, a criação de um estudo-piloto que posteriormente possa ser aplicado a uma amostra maior de objetos de aprendizagem desse tipo. Capturas de tela foram colhidas e a posição de cada quadro dentro da minutagem do vídeo foi anotada para facilitar posterior navegação por seu conteúdo. Além disso, cada captura foi classificada a partir do conteúdo ali apresentado, conforme veiculassem sequências em vídeo, animações ou imagens estáticas, por vezes ocorrendo a sobreposição de algumas dessas categorias. Ao todo, 75 capturas de tela foram colhidas em resolução máxima, no formato 1280 × 800 pixels. 


\section{Análise}

A decupagem do episódio de Crash Course Computer Science escolhido para análise permitiu a identificação três tipo de conteúdo, por vezes usados de forma híbrida:

1. filmagens (da apresentadora, em geral sofrendo intervenções animadas sobrepostas ao vídeo conforme o tema de sua fala),

2. animações (em linguagem esquemática, verbal e pictórica; às vezes em tela cheia, às vezes inseridas por sobre as filmagens), e

3. imagens de banco (imagens fotográficas estáticas ou filmagens de banco de imagens, com efeito vinheta e intenção de contextualização).

Figura 2: Filmagens, animações e imagens de banco usadas no Crash Course. Fonte: das autoras.

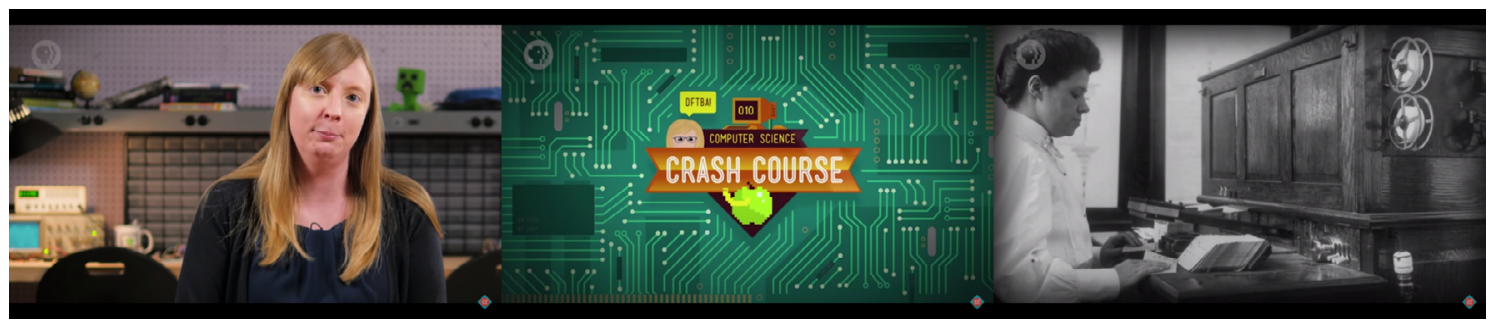

Foram identificadas também cinco categorias de uso desses elementos gráficos, conforme seu emprego no contexto da explicação:

1. as já citadas imagens de banco (usadas em tela cheia com pouca interferência de outros tipos de mensagens),

2. elementos verbais (animados, sobrepostos ao vídeo, chamando atenção para conceitos e termos importantes; blocos de citação ou conceituações mais elaboradas),

3. representações pictóricas individuais (ilustrações animadas com intuito de ilustrar e/ou comparar; por vezes combinadas a outros elementos),

4. inserções combinadas ao vídeo (ilustrações e esquemas veiculados junto à fala da apresentadora, emolduradas em um bloco específico, contextualizando ou exemplificando sua fala), e

5. tabelas, diagramas e estruturas informacionais em tela cheia (diagramas padronizados conforme a notação utilizada na eletrônica computacional e suas tabelas de saída correspondentes). 
Figura 3: Elementos verbais, pictóricos e esquemáticos no Crash Course. Fonte: da autora.

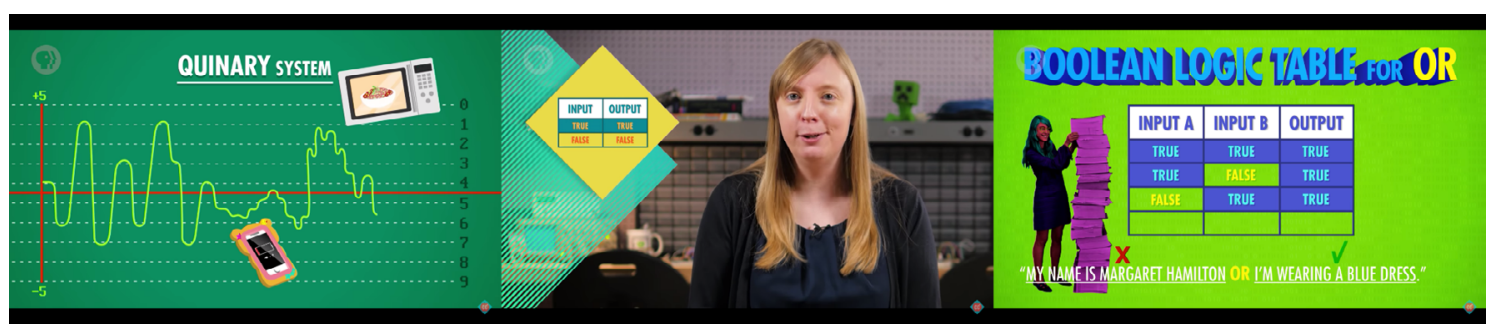

A partir das relações entre os elementos e as operações retóricas conforme estruturadas por Durand (quadro 1), buscou-se identificar as figuras de linguagem presentes neste material do Crash Course com vistas a distinguir de que forma se exerce o manejo dos significados e significantes na linguagem gráfica do canal. Essas categorias não extinguem as possibilidades dentro do conjunto disponível de figuras de linguagem, mas se mostram apropriadas para a presente análise, dado que as relações que classifica estabelecem relações comparativas entre significantes e significados, essenciais ao propósito instrucional-pedagógico.

Em um primeiro momento, algumas das manifestações de linguagem identificadas no discurso visual do curso em questão parecem abarcar mais de uma figura retórica ao mesmo tempo. Sendo o código imagético aberto a várias possibilidades interpretativas, para os propósitos deste estudo optou-se por destacar aquelas que mais fizessem sentido de acordo com a intenção comunicacional primordial do material. Cinco das ocorrências de uso de linguagem figurada serão destacadas e discutidas aqui, tendo como parâmetro para essa escolha o conteúdo retratado e as relações que ele estabelece com outras partes do tópico.

Logo de início, a primeira figura retórica identificada no Crash Course Computer Science é a da analogia (minuto 0:49): ao se referir aos dois estados possíveis da corrente elétrica (ligado e desligado) e a representação de informações que esses estados permitem, Carrie Anne associa o radical "bi-" de "binário" às duas rodas de uma bicicleta e à característica bípede dos humanos que os permite caminhar sobre duas pernas. Esse exemplo simples demonstra a natureza ampla dos significados presentes na linguagem gráfica: ao fazer essa analogia e se utilizar de dois exemplos, a mensagem é reforçada através da comparação e da repetição, além da relação de similaridade entre os termos com base em sua etimologia.

Figura 4: Binário, bicicleta e bipedalismo possuem o mesmo radical. Fonte: das autoras.

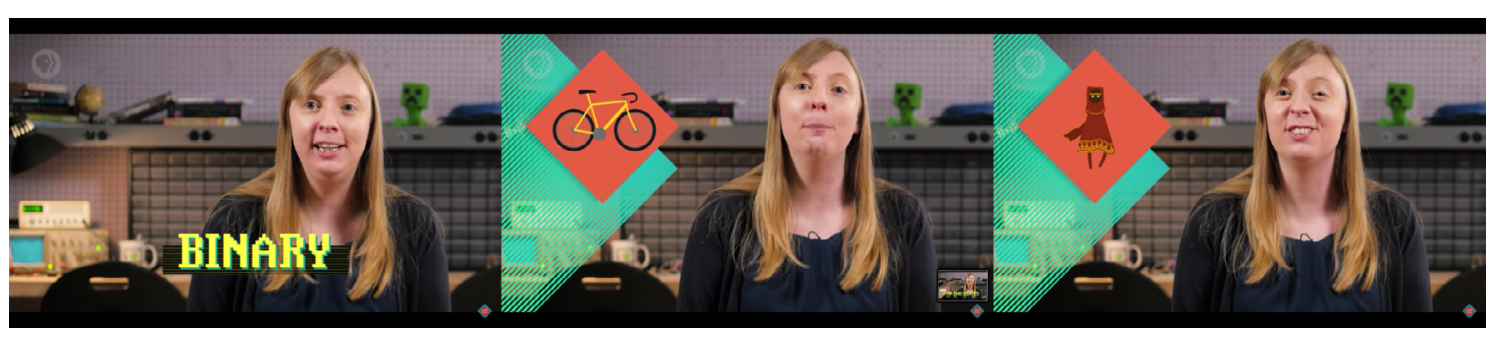

Mais adiante, ao apresentar George Boole, pai da álgebra booleana que viveu no século XIX, o vídeo traz uma pequena inserção de humor (minuto 2:05): em um quadrinho que 
aparece por poucos segundos ao lado de um retrato ilustrado sobre fotografia do matemático britânico - que exige pausa no vídeo para ser lido —, um trocadilho com o seu nome reforça o seu autodidatismo ao afirmar que Boole desenvolveu sua própria álgebra ("George grabbed the 'Boole' by the horns and developed his very own algebra!'). Dentro da categorização de Durand (op. cit.), a relação aqui estabelecida é uma falsa homologia, dado que Boole não laçou de fato boi algum - ao menos não no processo de sua criação matemática. Levando-se em conta o duplo canal em que essa mensagem é codificada, é possível identificar aqui também o uso da antanáclase: "Boole" é usado em dois sentidos, na criação desse trocadilho e também como nome próprio.

Figura 5: O matemático George Boole no material do Crash Course. Fonte: das autoras.

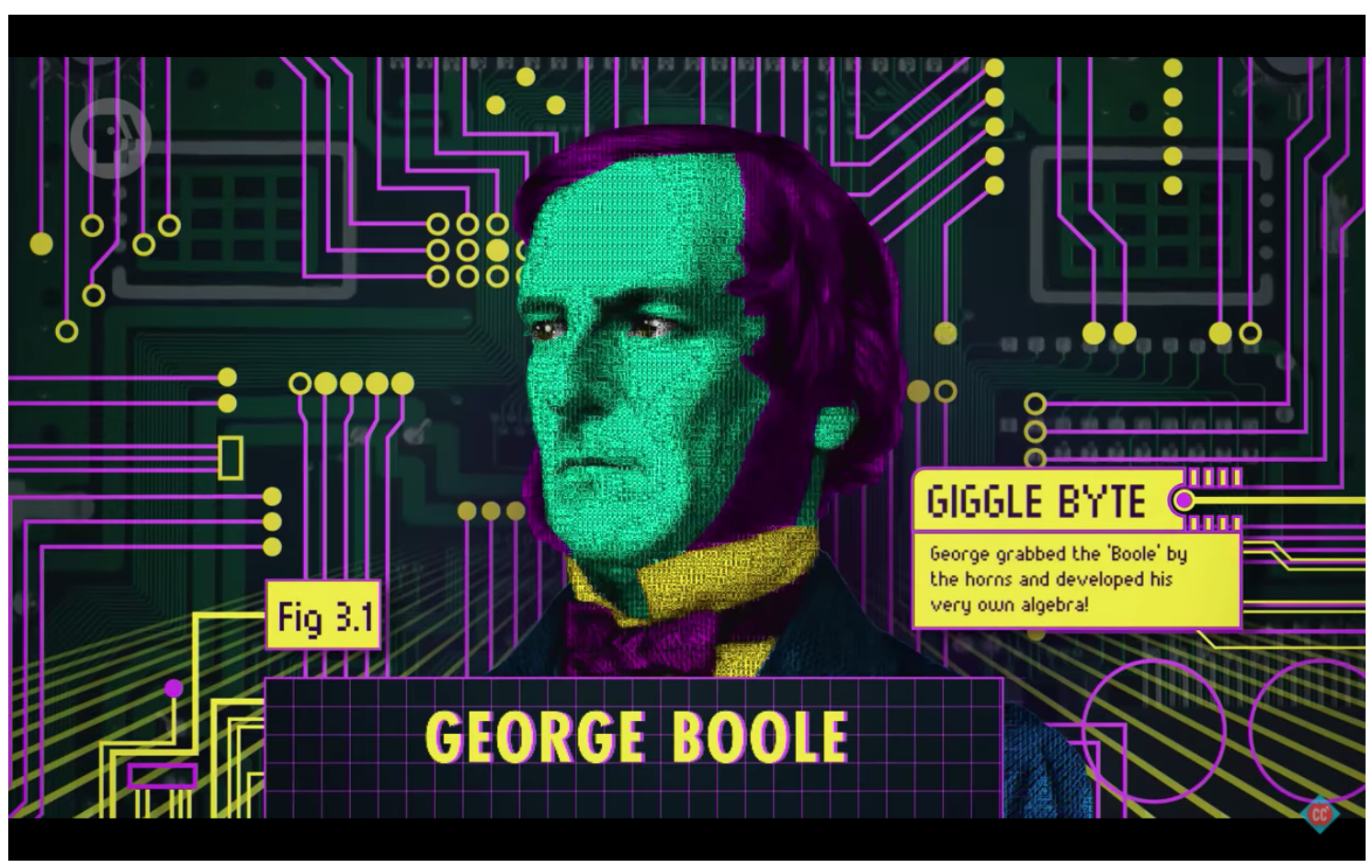

A imagem do fluxo de água que pode ser represado com uma válvula é usada em duas ocasiões neste episódio, ambas na explicação de como funcionam os transistores. Sendo esses componentes interruptores de sinal elétrico, a animação de uma torneira é apresentada em seguida ao esquema diagramático elétrico (minuto 3:27), em destaque à esquerda da tela, ilustrando a fala da apresentadora. Essa mensagem é reforçada adiante (minuto 4:15) através de imagens de adutoras com grande fluxo e um chuveiro sem água, ambas ilustrando um outro exemplo onde a passagem da corrente elétrica é desviada e gera como saída o sinal de "desligado" ("false" na lógica booleana). Tal uso desses signos imagéticos - a depender das mensagens complementares do canal auditivo, por vezes metafórico, por vezes analógico é especialmente importante porque ilustra um conceito usado durante todo o vídeo, que é a alteração entre os estados "false" e "true". 
Figura 6: Carrie Anne explica o funcionamento das portas lógicas no Crash Course. Fonte: das autoras.

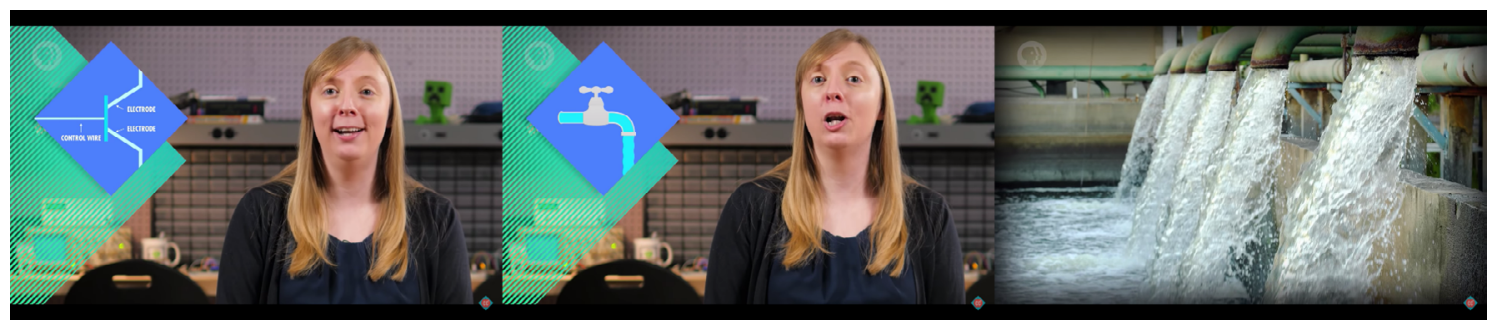

Ao apresentar a tabela do esquema da porta lógica XOR (OR exclusivo) - cujas operações resultam em uma saída "true" caso o número de entradas "true" seja ímpar — utiliza-se a figura retórica da analogia. Para ilustrar a saída verdadeira a partir de opções mutuamente exclusivas, o exemplo análogo é o de uma refeição cujo acompanhamento só pode ser um ou outro: sopa ou salada (minuto 7:34). Animações de caráter pictórico ilustram esse exemplo, trazendo leveza e humor à tabela, que codifica abstratamente esse conhecimento.

Ainda dentro do assunto da porta lógica de tipo XOR, ao desenvolver essa explicação a partir de um exemplo que mostra que a estruturação dessa porta lógica resulta da combinação das outras três, Carrie Anne fala da notação técnica dessa porta (minuto 8:35). Aqui também muitas figuras de linguagem sobrepostas podem ser identificadas: existe o reforço de uma mensagem que já foi veiculada (repetição), a comparação do símbolo da notação técnica com formatos específicos ("foguete" e "sorriso", se tratando de analogia ou metáfora, conforme o contexto provido pelo canal auditivo), comparação essa que é arrematada pela própria linguagem corporal da apresentadora, que sorri (hipérbole).

Figura 7: Tabela para o comparador XOR e sua notação técnica no Crash Course. Fonte: das autoras.

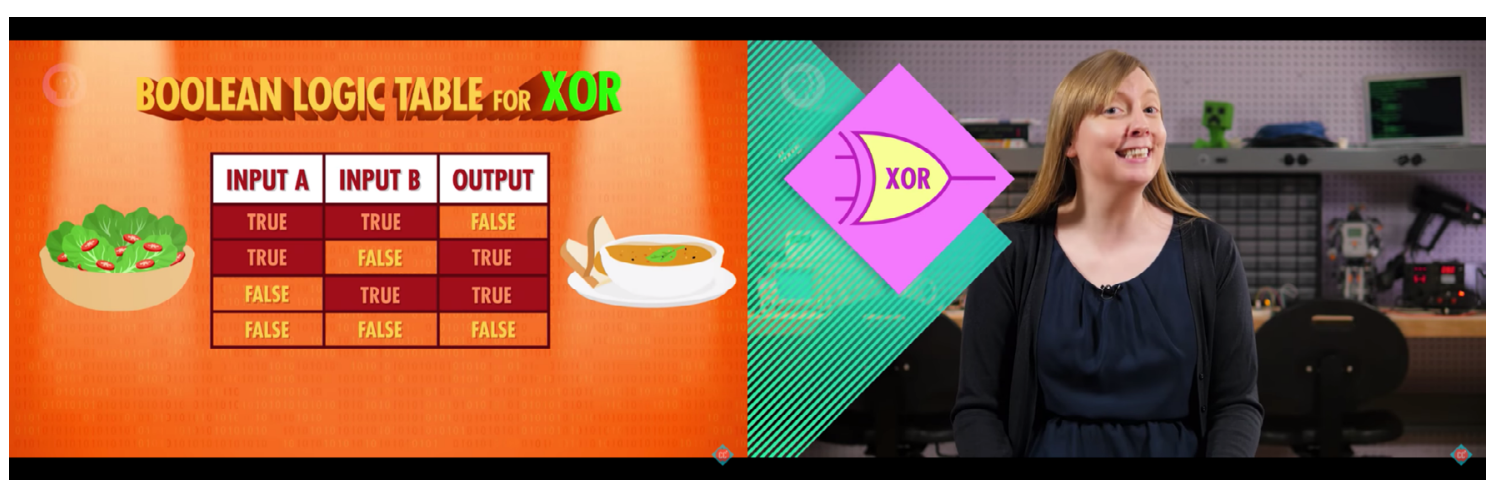

A partir dessa análise, é possível identificar o uso de linguagem figurada nesse material principalmente quando existe o uso de representações pictóricas, mas não só - vide as relações de significado estabelecidas a partir dos símbolos abstratos das portas lógicas (figura 7). Relativo às categorias de Durand (1974), existe um predomínio do uso das relações de similaridade e identidade nas operações retóricas empregadas. Além disso, foi possível notar que certos sentidos transmitidos no canal visual e verbal só podem ser corretamente compreendidos ao serem contextualizados pelas informações fornecidas pelo canal auditivo, 0 
que reforça a relevância dos estudos de Mayer (2012), Sweller (2012) e Paivio (1986), citados anteriormente neste trabalho.

No que diz respeito à construção de modelos mentais, o conteúdo técnico é esquemático, dada a natureza abstrata do assunto tratado. Eles ajudam os estudantes a construírem relações de comparação, analogia e sequências entre os diferentes conceitos. Eles representam processos e percursos, e o vídeo se vale muito bem da linguagem audiovisual para demonstrar essas abstrações através de exemplos animados. Dado esse caráter abstrato inerente ao assunto, é importante que se faça uso das imagens na abordagem do tema, tanto em sentido denotativo (quando contextualiza a tecnologia historicamente ou ilustra um conceito, por exemplo) quanto conotativo (no uso de linguagem figurada). $O$ tratamento que se dá ao assunto no Crash Course não se aprofunda no baixo nível da infraestrutura computacional, conhecimento necessário a quem opera em nível de hardware, mas intenta dar uma visão geral desse funcionamento; essas noções básicas são conceitos fundamentais a qualquer pessoa que busque interagir um pouco mais profundamente com computadores, e isso é enfatizado no vídeo (minuto 8:52). O que esses esquemas ilustram são processos diferentes que podem acontecer em um mesmo percurso, e este pode ser montado de maneiras diferentes, dado que seus componentes são peças modulares.

Outro ponto importante a se ressaltar é a construção da linguagem do Crash Course propriamente dito. Seu estilo gráfico, ainda que dentro de uma identidade coesa compartilhada por materiais de todo o projeto, possui particularidades evidentes na série sobre Ciência da Computação. É o caso do uso de características gráficas que evocam ao passado da área: o uso da vexelart - estilo pixelart aplicado em meio vetorial - nas ilustrações e na tipografia fazem referência direta a uma época em que a baixa resolução era a característica principal das imagens geradas por essas máquinas. Essa "aura retrô" é identificável também no efeito vinheta aplicado nas bordas das imagens de banco, na tela animada que apresenta George Boole e nas molduras das citações, que imitam caixas de diálogo de sistemas operacionais antigos. O humor também é um ponto importante na construção dessa linguagem, uma vez que dá o tom da abordagem pedagógica, alivia as eventuais ansiedades dos estudantes em relação à complexidade inerente do conteúdo e reforça o caráter "amigável" da proposta educacional do canal.

\section{Considerações finais}

Este artigo apresentou uma pesquisa exploratória e analisou material em vídeo, em uma tentativa de efetuar articulações teórico-práticas necessárias a pesquisas subsequentes. Seu propósito foi o de identificar e discutir figuras da retórica em uso na série Computer Science do canal Crash Course no YouTube. As possibilidades analíticas de um conteúdo dessa natureza são várias pelas próprias características intrínsecas da mídia do vídeo, o que ressaltou a necessidade de se recortar seu o escopo, focando-se nas categorias da retórica visual de Durand (1974) e na proposta de Mayer (2012) para a educação multimídia. Tal abordagem 
propicia a identificação de certos padrões nos modos de simbolização deste caso específico e faculta a criação futura de frameworks de análise mais robustos.

O uso de múltiplos modos de representação na codificação do conteúdo no exemplo analisado demonstra as suas possibilidades de aplicação em um contexto onde o assunto tratado é bastante complexo e abstrato. Essas formas de codificação, conforme a articulação de teorias realizada neste trabalho aponta, podem ser de grande valor para os estudantes, dado que influenciam diretamente na possibilidade deles de fixarem esses conteúdos. Fica evidente, portanto, a parceria entre, de um lado, educadores e elaboradores de conteúdo, e do outro, dos estudantes no processo de simbolização e decodificação dos significados dos materiais didáticos. É flagrante a importância do Design da Informação neste processo.

O conteúdo educativo nas plataformas sociais de vídeo abertas como o YouTube evoca a tradição dos canais de televisão educativos. Como esses canais de televisão, os canais do YouTube estão sujeitos às formas de codificação de áudio e vídeo e, por mais que possam ter missões distintas de canais de entretenimento e informação, ambos são, essencialmente, canais de transmissão de vídeo. Essa discussão sobre o borramento das fronteiras entre os propósitos pedagógicos e de entretenimento, bem como dos locais onde esse tipo de material na internet é acessado (Machado, 2011) é interessante, mas não faz parte do escopo do presente trabalho. No entanto, é importante apontar que as formas como as mídias de entretenimento operam a linguagem acabam permeando as demais, e isso pode se dar porque os seus modos de codificação compartilham com elas objetivos primários: causar uma impressão duradoura na mente da audiência.

Facilidade de acesso deve ser, portanto, não apenas uma questão infraestrutural para a educação não-formal multimídia, mas a sua base de construção de significado. O caso do canal Crash Course é emblemático nesse sentido porque seu propósito na série sobre Ciência da Computação é precisamente o de tornar acessível um tipo de conhecimento que possui muitas camadas de abstração, se constrói fundamentalmente sobre conhecimento prévio e cuja área possui um histórico de controle deliberado do seu acesso na esfera formal (Lima, 2016). Ainda que a educação não-formal possa ser usada como uma "solução anti escola" para os problemas da educação (Afonso, 2001), a permeabilidade dessa modalidade pedagógica em formato vídeo - condicionada, obviamente, pelo alcance da infraestrutura de rede permite acesso e flexibilidade àqueles que estão fora dos ambientes escolares.

\section{Referências}

Afonso, A. J. (2001). Os lugares da educação. In: Von Simson, O. R. M.; Park, M. B.; Fernandes, R. S. (org.). Educação não-formal: cenários da criação. Campinas: Editora da Unicamp.

Andrade, R. C. (2020). Framework para design de infográficos: uma proposta a partir de um estudo de caso em infografia de saúde. Tese de doutorado. Programa de pós-graduação em Design. Curitiba: UFPR. 
Cook, M. P. (2006) Visual representations in science education: the influence of prior knowledge and cognitive load theory on instructional design principles. In: Science Education, 90(6). Disponível em: https://onlinelibrary.wiley.com/doi/abs/10.1002/sce.2016

Durand, J. (1974). Retórica e Imagem Publicitária. In: METZ, Christian. A Análise das Imagens. Petrópolis: Vozes.

Leib, B. (2012). Why Isn't School This Cool? In: Wired. Disponível em: https://www.wired.com/2012/03/scishow-crash-course/. Acesso em 16 de abril de 2021.

Lima, F. A. (2016). Depoimentos e Vivências de Mulheres nos Cursos de Computação da Universidade Tecnológica Federal do Paraná. In: Informática na Educação: teoria e prática, 19(3). Disponível em: https://www.seer.ufrgs.br/InfEducTeoriaPratica/article/view/59144. Acesso em 28 de abril de 2021.'

Jaworski, M. (2012). How YouTube is revolutionizing education. The Daily Dot. Disponível em: https://www.dailydot.com/society/youtube-education-john-green-pbs-idea-channel/. Acesso em 16 de abril de 2021.

Machado, A. (2011). Pré-cinemas e pós-cinemas. Campinas: Papirus.

Mayer, R. E. (2012). A Cognitive Theory of Multimedia Learning. In: Mayer, R. E. (ed.). Multimedia Learning. Cambridge: Cambridge University Press.

Morán, J. M. (1995) O vídeo na sala de aula. In: Comunicação e Educação, 2, 27-35. Disponível em: https://www.revistas.usp.br/comueduc/article/view/36131. Acesso em 18 de abril de 2021.

Oakley, B. (2014). A Mind for Numbers. Nova York: Tarcher/Penguin.

Paivio, A. (1986). Mental Representations: a dual coding approach. Oxford: Oxford University Press.

RaspberryPi.org. (2021). Raspberry Pi Foundation. Disponível em: https://www.raspberrypi.org/. Acesso em 18 de abril de 2021.

Sweller, J. (2012). Implications of Cognitive Load Theory for Multimedia Learning. In: Mayer, R. E. (ed.). The Cambridge Handbook of Multimedia Learning. Cambridge: Cambridge University Press.

The Webby Awards. (2021). Crash Course: Honoree. Webby Awards. Disponível em: https://winners.webbyawards.com/2018/video/video-series-channels/science-educationvideo-channels-series/42425/crash-course. Acesso em 16 de abril de 2021.

Zipkin, N. (2018). The Simple Question the Producers of the Wildly Popular 'Crash Course' Ask Themselves When Creating Content. Entrepreneur.com. Disponível em: https://www.entrepreneur.com/article/322929. Acesso em 16 de abril de 2021.

\section{Sobre as autoras}

Fabiane Alves de Lima, MSc., UFPR, Brasil <fabianelim@gmail.com>

Carolina Calomeno Machado, Dr., UFPR, Brasil <carolcalomeno.ufpr@gmail.com> 